\title{
Chain of cycle of money
}

\author{
Constantinos Challoumis
}

\begin{abstract}
This paper researches the chain of the cycle of money. It is scrutinized the aspect of the application of the cycle of money with and without the enforcement of financial savings and/or the escaped financial savings. This work supplied the minimization and the case of maximization of the cycle of money. Consequently, it has declared the chain of money. Thus, scrutinized the case that there's a lack of the enforcement financial savings and in the end the case that there have disregarded the escaped financial savings. Therefore, exists an evaluation that stands at the application of the general public region and the application of the out of control enterprises. Thus, acquired effects approximately the application of the cycle of money displaying the factors and the behaviors of any financial system while there are and while there are no enforcement financial savings and/or the escaped financial savings. Concluding this work exhibits that a financial system that has an excessive frequency of the use of cash in its monetary, succeeds to have higher overall performance and social prosperity. The choice of G7 for the minimal tax fee of 15\%, globally, complies with the closing acknowledgments of the fixed-length principle of the cycle of money. The structure and the dynamic of the economic system are affiliated with the reuse and distribution of money. For this scrutiny is used firstorder derivatives below conditions, the Karush-Kuhn-Tucker approach, and the Q.E. logic.
\end{abstract}

.JEL classification: B41, F6, F40, F43, F62, F63

Keywords: chain of cycle of money, escaped savings, enforced savings, G7 decision, fixedlength principle, minimum tax

\section{Introduction}

The paper "Analysis of the theory of the cycle of money" is the root paper for the current analysis (C. Challoumis, 2020). The dynamic of the economy is expressed through the impact of the cycle of money. Thus, the cycle of money is strong abides by the dynamic of the economy, meaning the impact of the cycle of money, pending with the enforcement and the escaped savings. Furthermore, controlled transactions in the theory of the cycle of money are not considered only the international transactions, but any type of administration of tax administration, basically from the larger companies, those who substitute commercial activities for the smaller ones. Then, the investments in factories and know-how technological companies have a positive effect on the economy, and more specifically in the cycle of money. The cycle of money presents that an economy should apply the fixed-length principle, meaning that should be implied additional taxes to international companies, as the arm's length principle leaves a wide area to the companies that participate in controlled transactions to choose the method they like to present to the authorities about their tax obligations (Feinschreiber, 2004). The concept of the cycle of money suggests that the appropriate economic policy is that which protects the smaller and medium companies from high taxation. The only big companies that should have low taxes are the factories and the technological know-how companies (Anguera-Torrell, Aznar-Alarcón, \& Vives-Perez, 2020; Bowling, Boyland, \& Kirkeby, 2019; Constantinos Challoumis, 2018, 2021b; Fernandez \& Raine, 2019). A key role has the dynamic of the economy, which is boosted by the positive impact of the enforcement savings, and by the diminish of escape savings.

Constantinos Challoumis

National and Kapodistrian University of Athens

e-mail: challoumis_constantinos@yahoo.com 
Then, the larger companies should not proceed to activities that smaller ones. The main concept is that the small-medium companies and the freelancers increase the consumption and the savings for the economy. The consumption is increased as more economic units are in an economy, meaning citizens, small and medium enterprises. The reason for that situation is that the freelancers, the small and medium companies are the main parts of an economic system. The real savings are increased because these savings will return to the real economy. Most savings of the bigger companies are saved to tax heavens and overseas banking systems, and this money is lost from a country's economy. Thus, the dynamic of the economy is increased by the positive impact of the cycle of money. The economy which has a higher impact on the cycle of money is more well structured, meaning that is more social, as more money is distributed to more economic units, therefore the whole society is positively affected. If a country has high GDP, but contemporaneously has a low cycle of money, then this economy doesn't have a social profile. A metaphor is that "the economy is like a balloon and the money is the air of the balloon. If no air is left or entry to the balloon, the balloon will stay with some air. Then the loss of air happens when the larger companies are saving huge amounts of money to tax havens and external country's banking systems, with his money, never come back to the country's economy” (Forson, 2020; Ginsburgh \& Weber, 2020; Haigh, 2020; Loayza \& Pennings, 2020; Mackean, Fisher, Friel, \& Baum, 2020; Michener \& Brower, 2020; OECD, 2020a; Spiel, Schober, \& Strohmeier, 2018).

\section{Literature Review}

Using the theory of the cycle of money determined some basic concepts, which are the key elements for the maximization of the utility, for the tax authorities. The basic concepts are the fixed-length principle, the large scale companies, the small and medium enterprises, the consumption, the investments, the enforcement savings, the escaped savings, some quality factors as the health care system and the education, etc. Then, presented the following:

- The fixed-length principle is important for the improvement of the dynamic of the economy. The taxations of the companies which participate in controlled transactions must be subject to the fixed-length principle (Constantinos Challoumis, 2019b, 2019a). The fixed-length principle succeeds to imply a fixed minimum tax to the companies which participate in controlled transactions. In that way, the authorities can face tax evasion, securing that smaller companies will have activities, without exogenous economic impacts.

- Some economic units should have lower taxation because in that way would boost the economy. The units which could not be substituted should have lower taxation (i.e factories, R\&D -Research and Development Centers). The factories are a special case of big companies and should be taxed as lower as this is plausible. The main thought behind this choice is that factories significantly increase a country's GDP and at the same time are not substitute commercial and financial activities of smaller companies. The same context is about the high know-how technological companies, as these companies are not substituting smaller ones.

- Moreover, should be low the taxation rate, to the economic units which enforce the economy. Then, the taxation of middle and small companies should be very low, and the same should happen for the citizens because they are considered as small economic units. The medium and small enterprises are from a point of view the economy because are the parts of the economic system, as without them no economy and economic policy could exist. The distribution of money is increased by the growth of the population of the small and medium enterprises, then the distribution and the reuse of money are also increased. 
- In general, the wide investments (from the small and middle-companies) increase the cycle of money. Besides, the compact investments, from the big-size enterprises which substitute the small and the medium enterprises decrease the cycle of money. This doesn't happen for the factories and the R\&D centers, which use mixed savings. Based on the context of the prior points, the terms of compact and wide investments took sense. The compact investments in companies that substitute smaller companies' activities, lead to the depletion of the economy. On the other hand, wide investments increase the dynamic of the economy, as the distribution of money is more frequent, allowing more commercial and financial activities.

Using a different point of view, more specifically an opposite point of view, from the side of bog companies that substitute activities of small and medium enterprises, the theory of the cycle of money achieves a better definition. The key elements for the maximization of the utility, for the enterprises which participate in controlled transactions, are these:

- The robust economies should be established an appropriate economic environment for the enterprises of controlled transactions. The companies of controlled transactions should initially aim at economies with high financial liquidity. From the side of companies that are affiliated with controlled transactions, should target strong economies, as economies with a high cycle of money have better dynamics, allowing them more profits.

- The companies should change their behavior when the economies become weaker. Thence, when these economies become weaker by them, formed on the analysis of the cycle of money, they should change economic environments, and move to these economies which have a higher cycle of money. A weak economy is an economy with a low rate of the cycle of money. An economy with a low dynamic is not plausible to offer high profits to the big companies. Big companies cause a decrease in the cycle of money but can achieve high profits in economies with high rates until to make these economies weak.

- Thereupon, these companies could not be able to stay for long-term to any economy, as the enforcement savings, by their attitude, will be diminished by the increase of the escaped savings. These big companies cause a decrease in enforcement savings, increasing the same time escaped savings, therefore at some point in time should change an economy.

The context of the idea of the cycle of money hinged on the public and tax authorities must impetus small or medium companies with lower taxes and for the bigger companies to retain low taxes only for production units e.g. factories etc. The larger companies which substitute with smaller companies make weaker the economy as the money that they receive doesn't return to the economy and society. Escape savings is about the money which leaks from an economic system and doesn't return for investments, consumption, and reinvestments (Kananen, 2012; OECD, 2020b). The economies mostly consist of Small and Medium-sized Enterprises (SMEs), then their substitution from bigger companies, with enormous profits for these bigger companies, make economies weaker; it happens disproportional reuse and distribution of money, and simultaneously money lost from the economies, because is saved to international banks and tax heavens. The tax heaves have a key role for the companies which proceed to controlled transactions, as allow them to save their money outside the economies, increasing in that way the escaped savings.

From the prior analysis, it is determined the adequate behavior of the authorities and of companies that participate in controlled transactions. Also, the larger companies will become 
monopolies or oligopolistic companies, and the economies will become weaker. Then, the authorities should increase the taxation on them, and if this doesn't happen then these companies would not have any more profits. The reason why these big companies will become weaker is that they will have commercial activities in economies with low dynamics. Therefore, according to these circumstances, companies should move to another economy, to increase their profits. Thus, this paper emphasizes the chain of the cycle of money.

The examination of the utility of the cycle of money with and without the enforcement savings and/or the escaped savings is specified through the utility of companies and the utility of the authorities. Then, are used derivatives about the utilities of the companies and the authorities. Therefore, after calculations were received the utility graphs, which used to conclude the behavior of the cycle of money with and without the enforcement and/or the escaped savings. It should be noticed that used the velocity financial liquidity (or, the impact factor of financial liquidity), and the case of the velocity of enforcement savings (or, impact factor of enforcement savings). Since that:

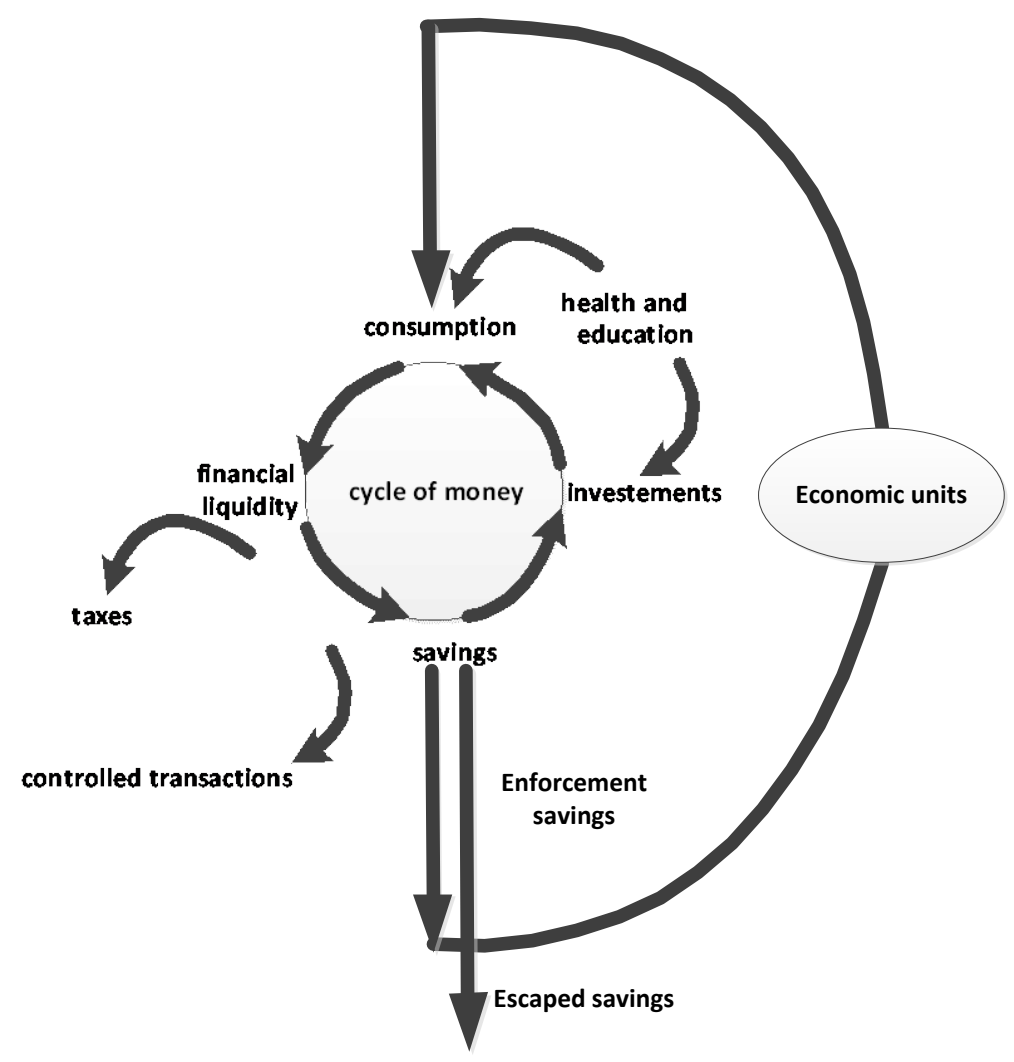

Figure 1 Chain of the cycle of money

The key points contained in the previous scheme are the key elements of the chain of the cycle of money. The cycle of money has four important points which are:

- Consumption increases the cycle of money. Consumption has a positive impact on the dynamic of the economy, as more consumption happens the distribution and additionally the reuse of money is increased. Therefore, consumption leads to a better 
cycle of money, where all the parts of the economy are used in a better way. Consumption affects the enforcement saving if the money goes to small and medium enterprises, otherwise affects the escaping savings, if it is directed to larger companies that substitute activities of the smaller ones.

- The investments increase the cycle of money. Similarly, investments increase the cycle of money, as the dynamic of the economy is boosted. The reuse of money in the economy increases by investments, as capital has a positive impact on the financial system. In the facet, that the investments happen for companies that substitute economic activities of smaller companies, then the result will be a negative result for the dynamic of the economy. On the contrary, if the investments happen for factories and know-how technological units the economy will be boosted. Finally, if aggregate smaller investments happen from the SMEs then, the economy will be enhanced.

- Financial liquidity increases the cycle of money. Financial liquidity is affiliated with the prior two terms. Then, consumption and investments increase the liquidity, as money is saved in local banks and it is plausible to be borrowed by companies and citizens, increasing that way the cycle of money. On the other hand, financial liquidity is increased by the direct distribution of money on the economy, through the economic units.

- The savings increase the cycle of money. The savings in the local banks increase the dynamic of the economy, interpreting that it increased the distribution of money and the reuse of money. Then, it is a different case the enforcement and the escaped savings. The escaped savings are savings outside the banking system of an economy, causing diminish of the cycle of money. At the same time, enforcement savings have a positive impact on the economy, causing an increase in the cycle of money.

In addition, the chain of the cycle of money is composed of the previous elements of the cycle of money and with the other four elements:

- The health system increases the cycle of money. The hospitals and in general the health system increase the distribution of money, mostly in long-term conditions. The expenses in the health system have a positive effect as this money secures the prosperity of the citizens. As a wider population has an economy, it is easier to have greater GDP, but this GDP must be in the same line with the theory of the cycle of money.

- The education system increases the cycle of money. The education system, as the same happens with the health system, is a long-term factor of the theory of the cycle of money. This means that plausibly has not an instant effect on the dynamic of the economy.

- The taxes decrease the cycle of money. Taxes harm the cycle of money as they decrease the money that is used in an economy. Therefore, the dynamic of an economic system is decreased by the impact of a tax rate. The tax rate should be as low as plausible to the companies that are factories, know-how technological units, small and medium companies, and citizens. The taxes should be high to the larger companies which substitute commercial and financial activities of smaller enterprises. In that way, the cycle of money will be boosted, and social prosperity will be ameliorated.

- The controlled transactions decrease the cycle of money. As controlled transactions are not considered only the administration of tax through companies, but any type of economic administration to avoid tax bureau. Then, the term the controlled transactions have a wider meaning in the theory of the cycle of money. 
Therefore, these eight points are the sources of the chain of the cycle of money. Pending on those economic elements, it is plausible to be defined as the behavior of the economy. The next section is given the basic principle of the cycle of money without enforcement savings.

\section{Methodology}

The contracts have a key role in the case of the tax administration by the companies. The same happens and from the agreements between the companies. Then, both the agreements and the contracts are used by the companies of controlled transactions, to administrate their tax bureau. The contracts and agreements are used for the allocation of earnings and losses. The agreements have to notify the adjustments withinside the contracts. Therefore, the tax government has to make periodic inspections. The periodic specification of contracts is important for the comparison evaluation and the arm's length principle. Then, the dedication of the cost-sharing relies upon the periodic take a look at of groups which are examined events. The reason for the groups of managed transactions is to keep away from excessive taxation (De Nederlandsche Bank, 2018). The necessities for the groups of managed transactions with the tax government have to be withinside the variety of the arms period principle. Thereupon, an appropriate settlement of the groups of managed transactions lets in the management of earnings and losses (Constantinos Challoumis, 2018; Jiang, Ding, Shi, \& Li, 2020; Lordo, 2001; Yen \& Langari, 1999).

In addition, must be notified that the groups of managed transactions and at the identical time the inspections of tax government are performed beneath the circumstance of the proportional changes (see appendix II). The interpretation of the circumstance of the proportional changes is that the groups which take part in managed transactions don't have ever an appropriate database and out-of-control transactions of comparable occasions to examine and consequently they proportionally regulate their databases. This manner that if the groups which might be examined events finish that the earnings and losses of groups from out of control transactions are plenty better or plenty fewer then they make the proportional analogy to examine them with their data.

Formed on the prior scrutiny:

$$
\begin{aligned}
& u=s(z f+\tilde{z} d) \\
& z=|\tilde{z}-1|
\end{aligned}
$$

The symbol $\mathrm{z}$ is a coefficient that takes values between 0 and 1 . The symbol $u$ is about the impact factor of the comparability analysis which has any method to the $s$. What value could receive is determined by the influence of the method (applying the best method rule) to the $s$. The symbol of $f$ is about the cost which comes up from the production of goods, and the symbol of $d$ is about the cost which comes from the distribution of the goods.

According to equations from (1) to (2), it is plausible to determine the following equations:

$u_{c}=z f+\tilde{z} d$

and

$\mathrm{b}=\left(\mathrm{p}-u_{c}\right)^{*} j_{1}$

The symbol of $b$ in the prior equation is about the amount of taxes that should pay the companies of controlled transactions in the application of the arm's length principle. The $u_{c}$ is the amount of tax obligations that can avoid through the allocations of profits and losses. Moreover, $j_{1}$ is a coefficient for the rate of taxes. Then, equation (3) shows the case of the arm's length principle. In the case of the fixed-length (Constantinos Challoumis, 2019b, 2019a) principle (which corresponds to the global minimum tax rate of $15 \%$ which is determined by G7): 
$v=\mathrm{p}^{*} j_{2}$

The symbol of $v$ according to the previous equation shows the taxes that should pay the enterprises of controlled transactions in the application of the fixed-length principle. Then, $j_{2}$ is a coefficient for the rate of taxes in the case of the fixed-length principle. Thereupon, it is concluded according to the prior theory that:

$v \geq b$

The tax for the companies which participate in controlled transactions of transfer pricing in the case of the fixed-length principle is higher or at least equal to that of the case of the arm's length principle. Thereupon, with the fixed-length principle, the enterprises of controlled transactions can administrate the allocation of profits and losses (Constantinos Challoumis, 2019a, 2019b).

Thus, the tax authorities can address the switch pricing (meaning the transfer pricing) consequences to the worldwide tax revenue. The fixed-length principle allows the recuperation of the tax losses of the worldwide tax revenue from the managed transactions of the switch pricing. This technique complies with the current selection of G7 for the minimal international tax charge of $15 \%$. This is mentioned withinside the beyond years via way of means of the idea of the cycle of money, approximately the assessment of arm's length principle and the fixedlength principle. The subsequent scheme has illustrated the technique that groups of managed transactions observe for his or her allocations of earnings and losses, the proportional modifications of data, and the fixed-length principle. Since that:

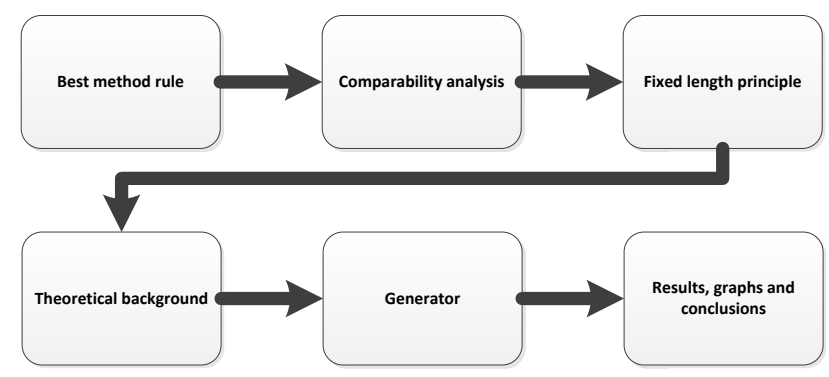

Figure 2 Cost sharing and application of fixed length principle

In figure 2 is specified the procedure of the fixed-length principle and its quantity analysis for the determination of the behavior of the model. The fixed-length principle has a key role in the theory of the cycle of money, as suggests a fixed tax to international transactions, avoiding the arm length principle. The tax revenues are identical to the financial savings that the businesses may want to have if the taxes had been avoided. The manner of those financial savings pends from case to case. The advantages of the businesses will be administrated differently, as will be stored or taxed. Then, the idea of the cycle of cash suggests while the financial savings sturdy the financial system and while the taxes sturdy the financial system. It is essential for this dedication to be a separation of financial savings into the non-back financial savings (or escaped financial savings) and into the back financial savings (or enforcement savings).

The equations of the theory of cycle of money:

$$
\begin{aligned}
& \alpha=\alpha_{s}+\alpha_{t}, \text { or, } \frac{1}{v}+\alpha_{t} \\
& x_{m}=m-a \\
& \mathrm{~m}=\mu+\alpha_{p}
\end{aligned}
$$




$$
\mu=\sum_{\iota=0}^{n} \mu_{\iota}
$$

$$
\alpha_{p}=\sum_{j=0}^{m} \alpha_{p j}
$$

$$
\begin{aligned}
& c_{m}=\frac{d x_{m}}{d m} \\
& c_{\alpha}=\frac{d x_{m}}{d a} \\
& c_{y}=c_{m}-c_{\alpha}
\end{aligned}
$$

The variable of $\alpha$ has symbolized the case of the escaped savings, interpreting the savings that are not returning to the economy or come back after a long-term period. The variable of $\alpha_{s}$ is the case that there are have escaped savings that come from transfer pricing activities. The variable of $\alpha_{t}$ is indicates the case that there are escaped savings, not from transfer pricing activities but any other commercial activity. For instance $\alpha_{t}$ is about the commercial activities that come from uncontrolled transactions. The variable of $m$ indicates the financial liquidity in an economy (Challoumis, 2019). The variable of $\mu$ indicates the consumption in an economy. The variable of $\alpha_{p}$ indicates the enforcement savings, which come from the citizens and small and medium-sized enterprises. The variable of $x_{m}$ is the condition of financial liquidity in an economy. The variable of $c_{m}$ indicates the velocity of financial liquidity increases or decreases. The variable of $c_{\alpha}$ symbolizes the velocity of escaped savings. Therefore, the variable of $c_{y}$ symbolizes the term of the cycle of money. Thereupon, the cycle of money shows the level of the dynamic of an economy and its robustness.

Then, the basic principles about the cycle of money are the following:

- Citizens, small and medium enterprises replaced by services and goods of companies that save their money outside the economy and do not invest or consume it commensurately in the economy. Thus, larger firms are the main cause of averted savings (i.e., savings exiting the economy and not returning to the economic system).

- The depletion of savings (interpreting the escaped savings) is the cause of the decline in the dynamics of the economy. The point of evading savings is that it is the responsibility of the regulated transfer pricing companies not to remit that money. This situation causes a lack of financial liquidity in an economy.

- It is a negation that the operation of factories and units of technological know-how cannot be replaced by citizens and small and medium-sized enterprises when it is not possible to justifiably provide the same added value to other businesses, products, and services. From there, those cases under appropriate tax policy will be taxed as uncontrolled transactions regardless of whether they participate in a controlled transaction or not (using the fixed-length principle).

- $\quad$ Enforcement savings have a positive impact on the economy. Execution economies are responsible for the strong economic dynamics of the economy. Therefore, investment and consumption are the factors that come from the savings of people and small and medium enterprises. 
- Financial liquidity (interpreting the velocity of financial liquidity) indicates how quickly the strength of the economy increases or decreases as a result. Then there is a clue to how well an economy is structured.

- The speed of savings fleeing (meaning the velocity of escaped savings), then the escaped savings indicates how quickly non-refundable savings are lost from the market, either by lack of investment or by lack of consumption.

- The money cycle (meaning the cycle of money) represents the state of the economy. The level of taxation is well structured. If this index is high, the economy is likely to have high sustainability, if not low financial liquidity.

- As controlled transactions in money cycle theory are not only considered transfer pricing cases, but also any form of profit and loss management to avoid taxation.

- An unregulated transaction (meaning uncontrolled transactions) in the theory of the cycle of money, recognized as commercial activity of citizens, small and medium enterprises, factories, research centers, and any kind of commercial activity, which cannot be replaced by controlled trading companies.

- $\quad$ The fixed-length principle deals with topics such as the cycle of money. But, this does not mean that the fixed-length principle should be strictly applied because the theory of the cycle of money is a broader theory that goes beyond transfer pricing. The fixedlength principle uses a fixed amount of tax rate, or in general tax, to the companies that take part in controlled transactions.

It follows that the money cycle thrives when there is a tax system such as the fixed-length principle that allows low taxes on uncontrolled transactions and higher taxes on controlled transactions. It should be mentioned that unregulated transactions are considered as financial liquidity of citizens, small businesses, medium enterprises, and any uncontrolled transactions. In addition, there are three basic influencing factors for tax incentives. (Abate, Christidis, \& Purwanto, 2020; Acs, Åstebro, Audretsch, \& Robinson, 2016; AICPA, 2017; AL-UBAYDLI, LEE, LIST, MACKEVICIUS, \& SUSKIND, 2021; Cai, 2017; Engström et al., 2020; Fronzaglia, de Moura Júnior, Racy, \& Vartanian, 2019; Goldsztejn, Schwartzman, \& Nehorai, 2020; Grove, Sanders, Salway, Goyder, \& Hampshaw, 2020; Kamradt-Scott \& McInnes, 2012; Maier, 2012; Montenegro Martínez, Carmona Montoya, \& Franco Giraldo, 2020; Oueslati, 2015; Ribašauskiene et al., 2019; Russo Rafael et al., 2020; TUTER, 2020). The corporate income tax is the only tax that has an immediate and significant role in the markets of any economy. These factors relate to the education, health system of each society and other structural economic factors related to the previous two factors. Then, using all the factors:

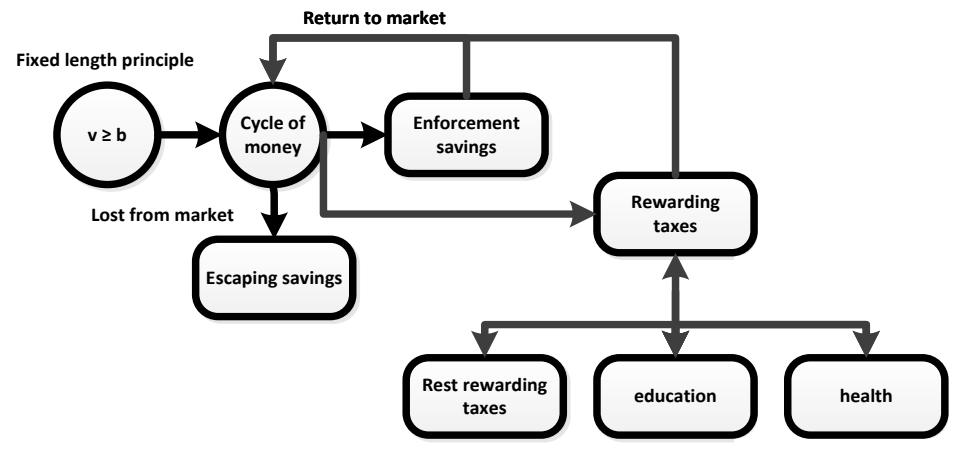

Figure 3 The cycle of money with rewarding taxes 
The rewarding taxes are mostly the factors that affect the economic system in its quality characteristics. In this case, are included all kinds of savings, meaning rewarding taxes, enforcement, and escaping savings. The quality characteristics of an economy are increased by the impact of the education and health care system. These factors are significant for any economy, more high tech, and in general advanced e.g. from the side of bureaucracy. The issue without enforcement savings is illustrated in the next scheme:

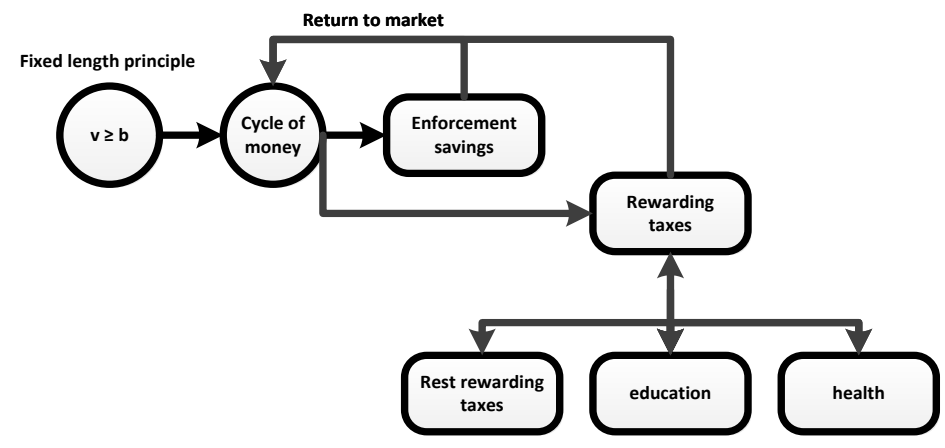

Figure 4 The cycle of money without escaped savings

An economy without escaped savings is an identical economy. In that condition, this type of economy will not lose its dynamic even if there is no monetary supply could happen. The issue without enforcement savings is illustrated in the next scheme:

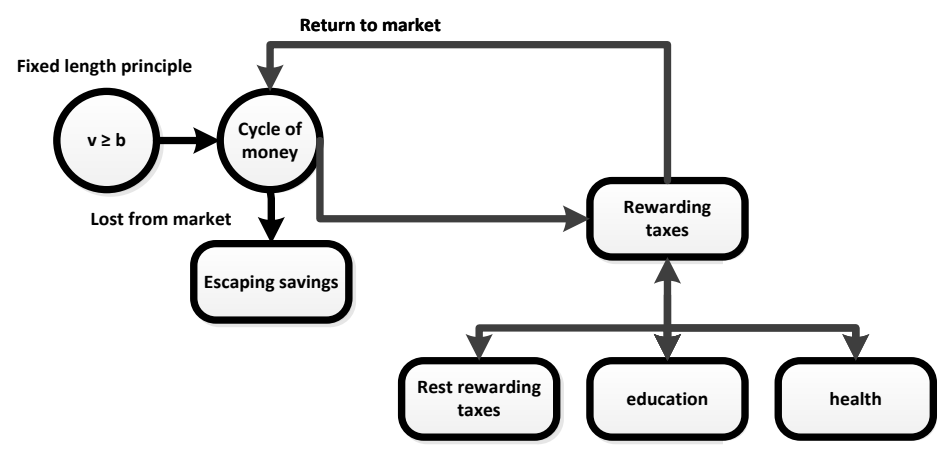

Figure 5 The cycle of money without enforcement savings

An economy without enforcement savings is a worst-case scenario economy. This economy at some point in time will have no liquidity and should have a constant monetary supply with money, to avoid collapse. Thus, Figure 5 represents the cycle of money additionally with all the rewarding tax factors. Then, for the rewarding taxes:

$\alpha_{p}=\alpha_{r}+\alpha_{n}{ }^{*} h_{n}+\alpha_{m}{ }^{*} h_{m}$

and

$\alpha_{r} \geq \alpha_{n}{ }^{*} h_{n} \geq \alpha_{m}{ }^{*} h_{m}$

The prior two equations used some impact factors, which are the $a_{p}$ which is also provided in equation (15), moreover the variables $\alpha_{r}, \alpha_{n}, h_{n}, \alpha_{m}$ and the $h_{m}$. The variable $\alpha_{r}$ shows the impact factor of the rest of rewarding taxes. The symbol of $\alpha_{n}$ is the impact factor of education 
and any technical knowledge. The symbol of $\alpha_{m}$ is about the impact factor of health anything relevant and supportive of this issue. The symbol of $h_{n}$, and of the $h_{m}$, are the coefficients of the health and the health impact factor accordingly. In the next section are determined the utilities of companies and authorities. Then, in the one case the factor $\alpha_{m} * h_{m}$, because there are no enforcement savings, approximate is zero. In the other case is used the factor of the $\alpha_{m}{ }^{*} h_{m}$. Additionally, there are two more cases, which are with and without the escaped savings, meaning with and without the factor of $\alpha_{n}{ }^{*} h_{n}$.

\section{Results}

For the mathematical determination of the utility cycle of money based on the equations that are subject to the utilities:

$$
\begin{aligned}
\widetilde{U}^{\prime}(t) & =\sum_{j=1}^{n}\left[c_{m} \widetilde{U}(\mathrm{t})-c_{\alpha} U(t)\right]_{j} \\
U^{\prime}(t) & =-\sum_{j=1}^{n}\left[c_{\alpha} U(t)\right]_{j} \\
U(0) & >0 \\
\widetilde{U}(0) & >0
\end{aligned}
$$

According to the prior clarifications should be noticed that the symbol of $\widetilde{U}(\mathrm{t})$ is about the utility of the authorities and therefore of the public sector. The symbol of $U(t)$ is about the utility of the companies which participate in controlled transactions. If equations (17) - (20) are satisfied then it is indicated that as higher is the frequency that an amount of money is used in an economy, then higher is the status of this economy:

$m_{f}=c_{y} * G D P$

The variable of $m_{f}$ represents the frequency of cycle of money. Where, $c_{y}$ takes values from zero to one. Using equations (1) to (20) it is possible to declare the behavior of the utility of the cycle of money (see appendix II). Then, using all the factors, meaning the case that used both, the escaping savings and the enforcement savings, the magnitudes should have not a high divergence ( $c_{m}=0.197$, and $\left.c_{a}=0.198\right)$ (see Appendix I for the graphs):

(a)

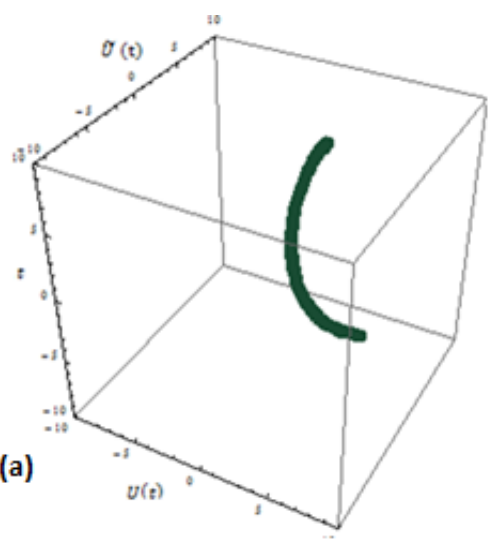

(b)

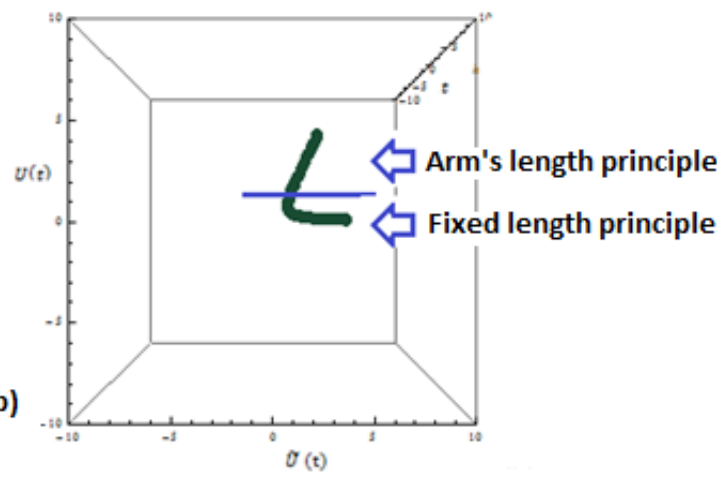

Figure 6 (a) Utility of cycle of money in three-dimension approach (b) Utility of cycle of money in three dimensions approach from a different view 
In the two graphs in the previous figure, it is concluded that there is a critical point where the utility curve changes slope (the symbol for t corresponds to the number of iterations, which is 20). This is then part of the fixed-length principle, where the utility of public authorities (public sector) is increased. The same goes for companies that engage in uncontrolled transactions (which fall into the same category from the perspective that both are winners in the case of lower taxes on uncontrolled transactions). Therefore, the fixed tax in the companies which participate in control transactions permits a better allocation of money in an economic system. In the arm's length principle, it is concluded that firms in controlled transactions have more utility. Since that:

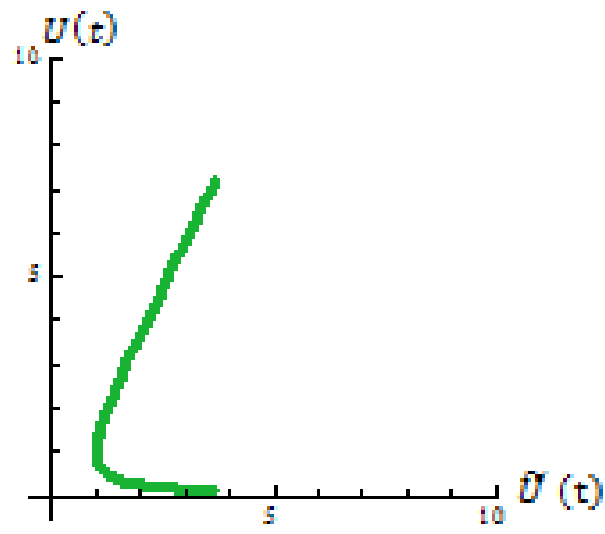

Figure 7 Utility of the cycle of money

From Figure 7, it is concluded that companies have more utility than authorities. This is expected, otherwise, no economic activity could happen. This is the rationale and risks that companies take to make business plans. In addition, there it is the important point that the utility of the authorities varies from the utility of the companies involved in controlled transactions. Using all factors, i.e. having both enforcement and escaped savings then their magnitudes should not have a high divergence $\left(c_{m}=1.5\right.$, and $\left.c_{a}=0.32\right)$ (see Appendix I for graph estimates):
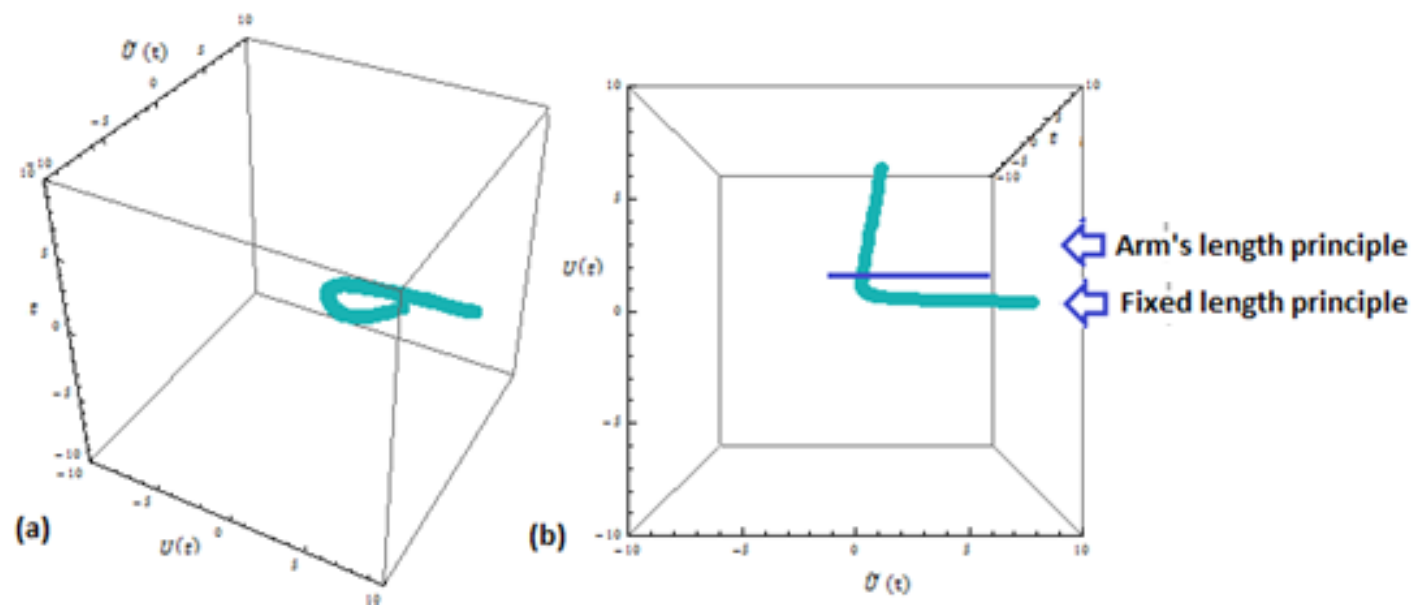

Figure 8: (a) Utility of cycle of money without escaping savings in three-dimension approach (b) Utility of cycle of money without escaping savings in three dimensions approach from a different view

Of the two graphs in Figure 8, it is concluded that there is a critical point where the utility curve changes slope (the symbol for t corresponds to the number of iterations, 20). Then, within the 
framework of the fixed-length principle, we get that the utility of the community (public sector) is increased. The curve of the escaping savings reveals the high negative impact of the escaping savings on the whole economy. The lost utility by the increase of escaping savings is significant for the economy, as the financial liquidity, and therefore the distribution and reuse of money, are declined. The same goes for companies that engage in uncontrolled transactions (which fall into the same category from the perspective that both are winners in the case of lower taxes on uncontrolled transactions). In the arm's length principle, the controlled trading firms achieve more utility. Thus, in the following figure:

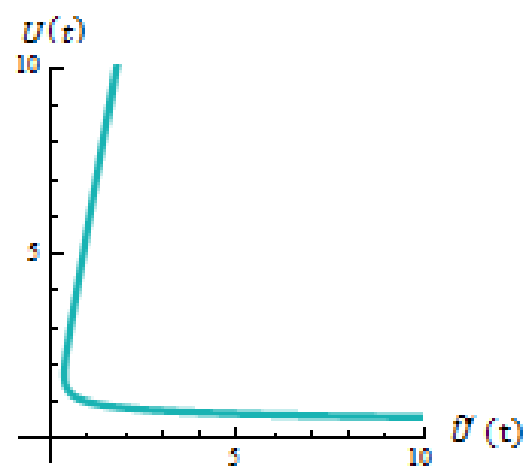

Figure 9 Utility of the cycle of money

According to figure 9, it is concluded that the authorities and then enterprises of uncontrolled transactions have higher utility than the enterprises of controlled transactions. But, in both cases it is concluded that the utility is generally very high in all cases, meaning the utility of the authorities, the enterprises of controlled transactions, and the enterprises of uncontrolled transactions. The reason for this situation is that an economy without escaping savings is much better than any other case. Moreover, it is specified again the critical point where the utility of authorities is changing from the utility of the companies which participate in controlled transactions. Using the one factor, therefore the escaped savings and the enforcement savings (approximately equal with zero), their magnitudes should have not a high divergence $\left(c_{m}=\right.$ 0.125 , and $c_{a}=0.86$ ) (see appendix for the estimations of the graphs) :
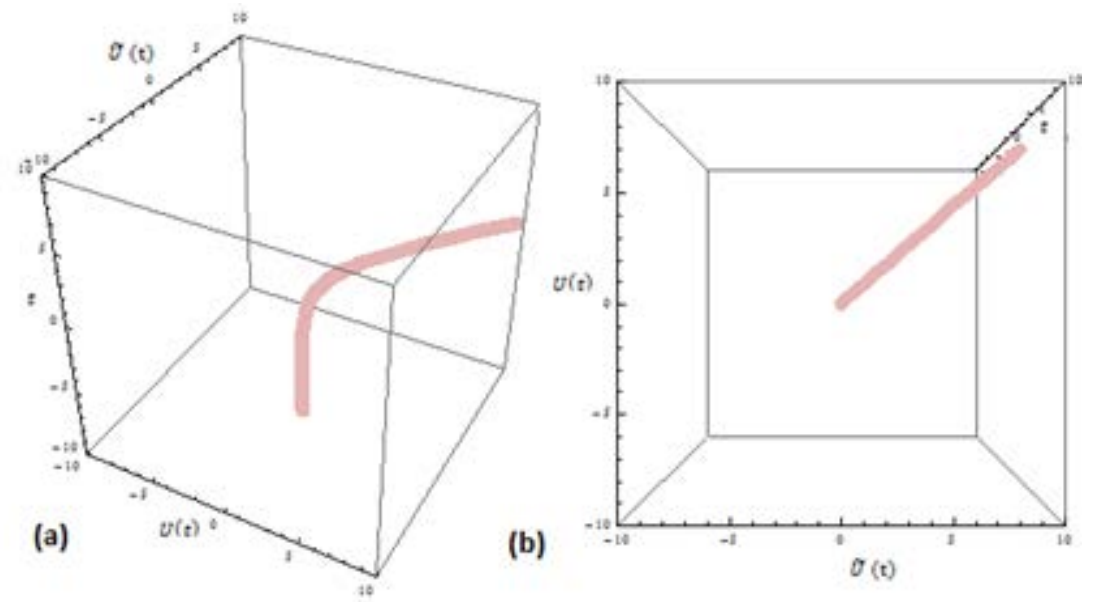

Figure 10 (a) Utility of cycle of money without enforcement savings in three-dimension approach (b) Utility of cycle of money without enforcement savings in three dimensions approach from a different view 
In the two graphs of figure 10, it is concluded that there is one critical point which is the point where the utility curve changes (the symbol of $t$ is about the number of iterations, which are 20). Then, it is the part of the fixed-length principle where the utility of the authorities (public sector) is increased. The same happens for the companies which participate in uncontrolled transactions (as belonging to the same side from the view that both win in the case of the lower taxation of uncontrolled transactions). In the part of the arm's length principle, it is concluded that the enterprises of controlled transactions have more utility. In the next figure:

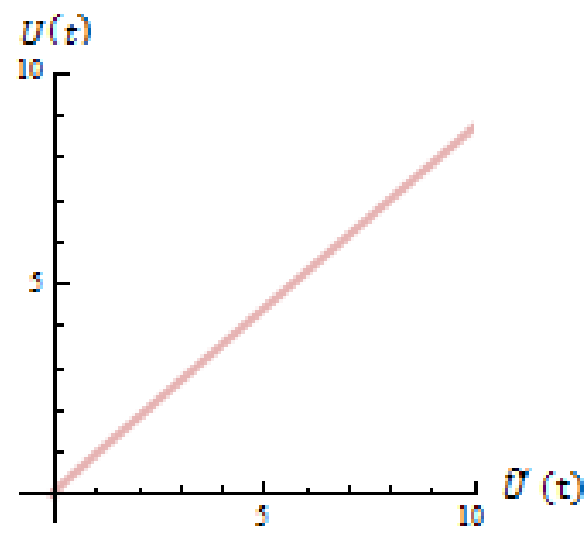

Figure 11 Utility of cycle of money without the enforcement savings

According to figure 11, it is obtained that the authorities and the enterprises of uncontrolled transactions have the same utility as the enterprises of controlled transactions. This interpretation of the current condition is that the utility of the authorities is the same as the utility of the enterprises of uncontrolled transactions. The dynamic of the economy stays stable, without waving, because there are no enforcement savings. Therefore, the cycle of the money stays stable and considering that if the escaping savings exist, then the dynamic of this economy will become lower. Using all the factors, meaning that there are both, the escaping savings and the enforcement savings, thence are used all the magnitudes in the one case. In the other case, the velocity of escaping savings is approximately equal to zero $\left(c_{m}=1.5\right.$, and $c_{a}=0.32$ ) (see appendix for the estimations of the graphs). Since that:

(a)

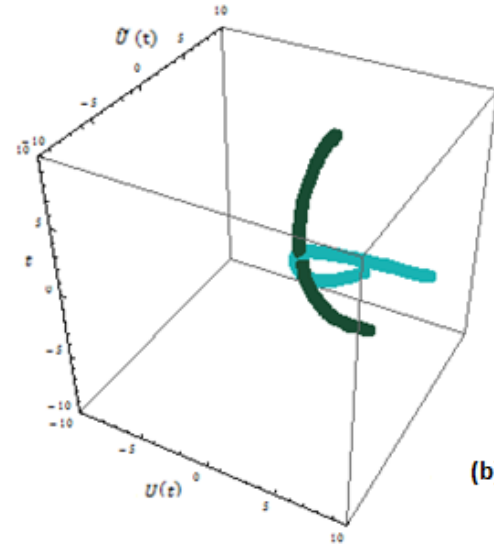

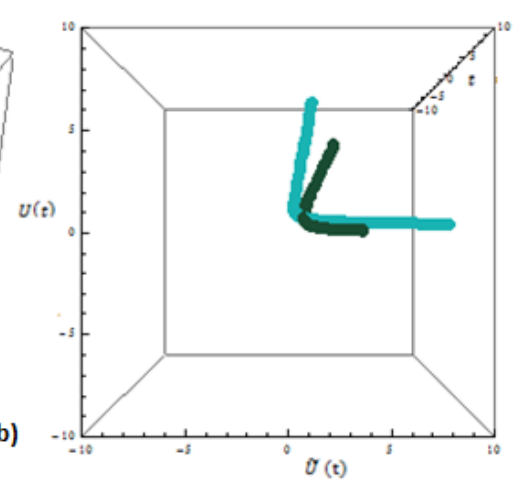

Figure 12 (a) Utility of cycle of money with and without escaping savings in three-dimension approach (b) Utility of cycle of money with and without escaping savings in three dimensions approach from a different view

In the two graphs in Figure 12, it is sufficient that there is a critical point where the utility curve changes (the symbol for $t$ represents approximately 20 repetitions). This happens in both facets 
because, in the case of escaped savings (green line) and the absence of escaped savings (blue line), and there is a changing point for public services. It is then concluded that the efficiency in the case of no escaped savings is higher than in the case of escaped savings. In the next

figure: e:

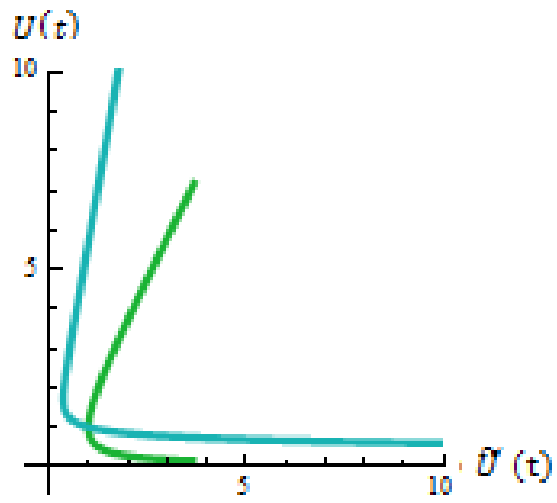

Figure 13 Utility of the cycle of money

According to the previous figure, it is identified that the utility is higher for the public and the private sector in the case that there are no escaping savings (blue line) than in the case that there exist escaping savings (green line). The utility is much higher in the case that there do not exist the escaping savings, compared with the case that there do not exist the escaping savings. Therefrom, the impact of the escaping savings negative effect on the dynamic of the economy, then on the cycle of money. These results are expected as the escaped savings harm the dynamic of the economy, and on the contrary, the enforcement savings have a positive impact on the economy. Thus, the utility of the economy and the economic dynamic in the version that there don't exist the escaping savings, is higher than in the case that there exist escaping savings. Using all the factors, meaning that there are both, the escaping savings and the enforcement savings, thence their magnitudes in one case. In the other case, the velocity of enforcement savings is approximately equal to zero $\left(c_{m}=0.125\right.$, and $\left.c_{a}=0.86\right)$. Since that:
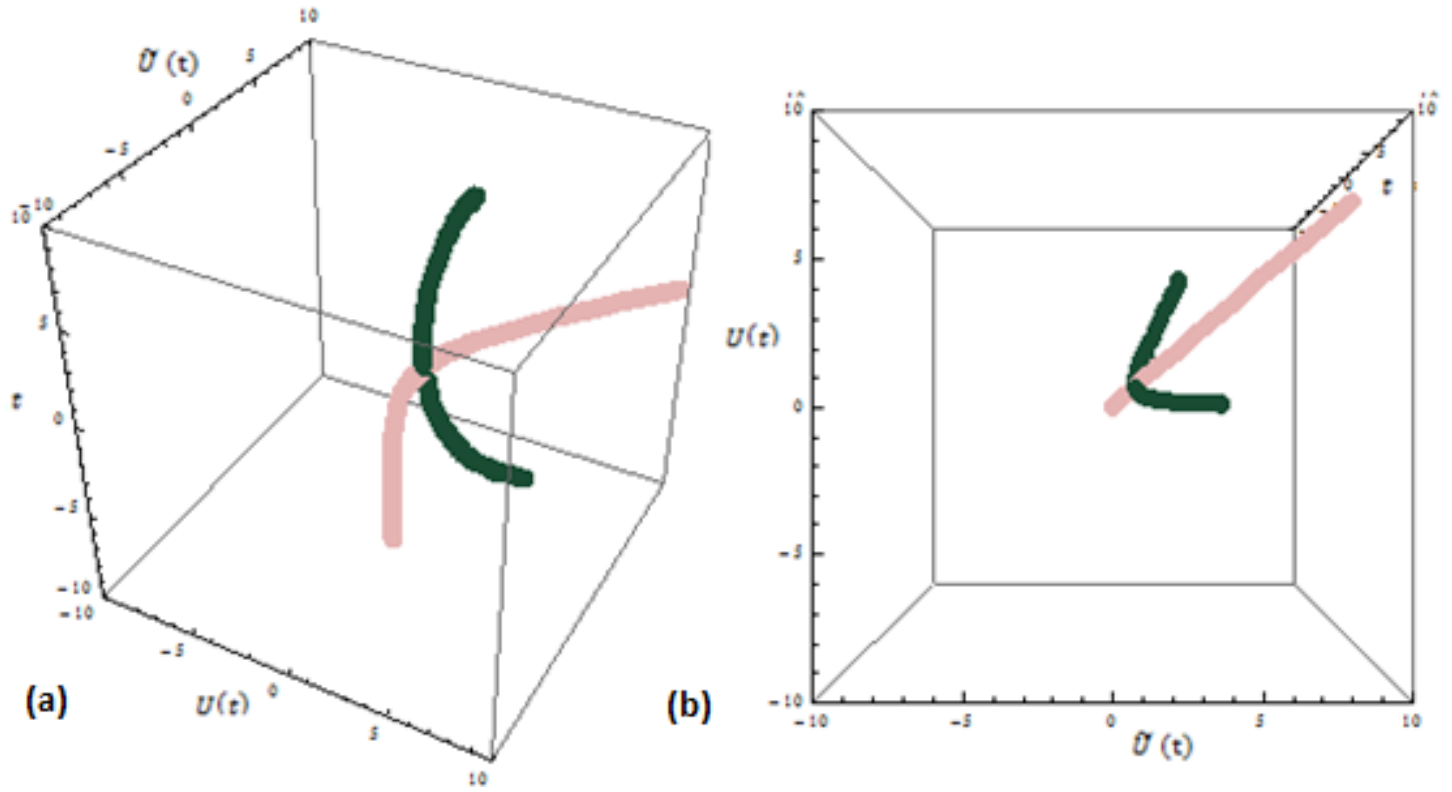

Figure 14 (a) Utility of cycle of money with and without enforcement savings in threedimension approach (b) Utility of cycle of money with and without enforcement savings in three dimensions approach from a different view 
In both diagrams of figure 14, it is concluded that there is only one critical point which is the point where the utility curve changes (the symbol of $t$ is about the number of iterations, which are 20). This happens in the case that there exist enforcement savings (green line) and it doesn't exist in the case that there are not the enforcement savings (pink line). It is well established according to the prior graph, that enforcement savings have a positive effect on the dynamic of the economy. Then, the enforcement savings lead to an ameliorated economy, with a high cycle of money. Then, it is obtained that the utility is higher in the case that there are enforcement savings than there don't exist the enforcement savings.

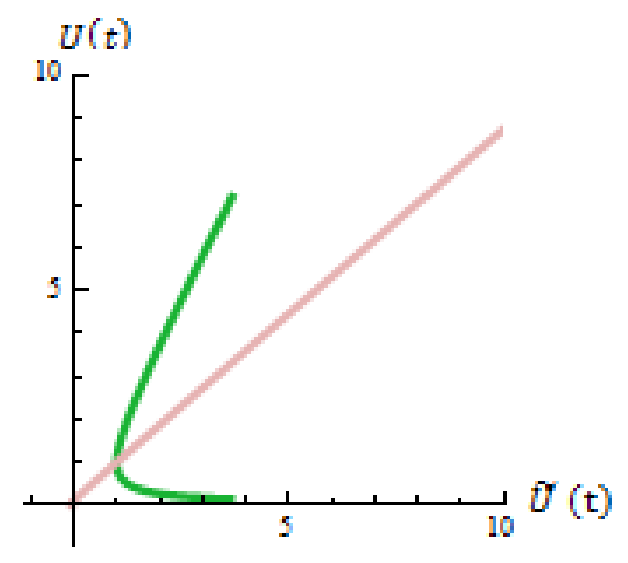

Figure 15 Utility of cycle of money with and without the enforcement savings

According to figure 15, it is concluded that the utility is higher for the public and the private sector in the case that there are enforcement savings (green line) than in the case that there don't exist enforcement savings (pink line). The line is a curve in the case of enforcement savings showing that there is a critical point, which permits the economy to have more utility than the companies which proceed to controlled transactions. In the facet, that there are no enforcement savings, the line offers equal utility for the authorities and the companies. This means that the companies of controlled transactions can administrate their profits showing saving their profits to tax heavens, and taxed only for the profits that show to the authorities. The curve line of enforcement savings indicates that the authorities can achieve better utility, than the showing profits that enterprises of controlled transactions provide to the government, Thence, the utility of the economy and the economic dynamic in the version that there exist the enforcement savings is higher than in the case that there are no enforcement savings. Using all the factors, meaning that there are both, the escaped savings and the enforcement savings, thence there are all the magnitudes in that case. In the other case, the velocity of enforcement savings is approximately equal to zero $\left(c_{m}=0.125\right.$, and $\left.c_{a}=0.86\right)$ (see appendix I for the estimations of the graphs). Since that: 

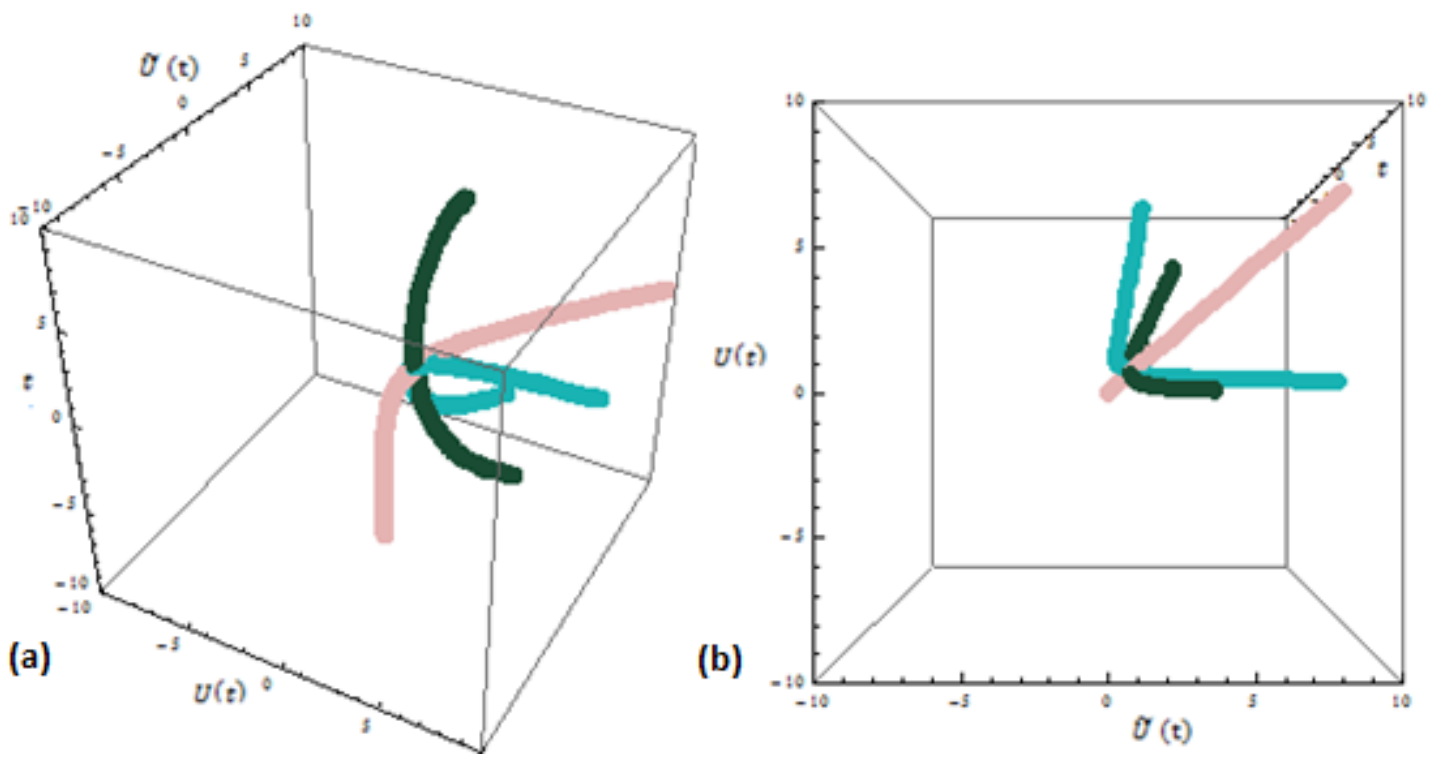

Figure 16: (a) Utility of cycle of money with and without enforcement savings and escaped savings in three-dimension approach (b) Utility of cycle of money with and without enforcement savings and escaped savings in three dimensions approach from a different view

In both graphs of the prior figure, it is concluded that there is only one critical point which is the point where the utility curve changes (the symbol of $t$ is about the number of iterations, which are 20) (for the normal case-green line and the case of absence of escaped savings-blue line). This happens in one case, in the case that there exist the enforcement savings (green line) and in the case of absence of escaped savings (blue line). This doesn't exist in the case that there are no enforcement savings (pink line). Then, it is obtained that the utility is higher in the case that there are enforcement savings than in the case that there don't exist enforcement savings. The normal case and the case (green line) of the no escaped savings (blue line) are higher than the case of enforcement savings (pink line). Since the next figure:

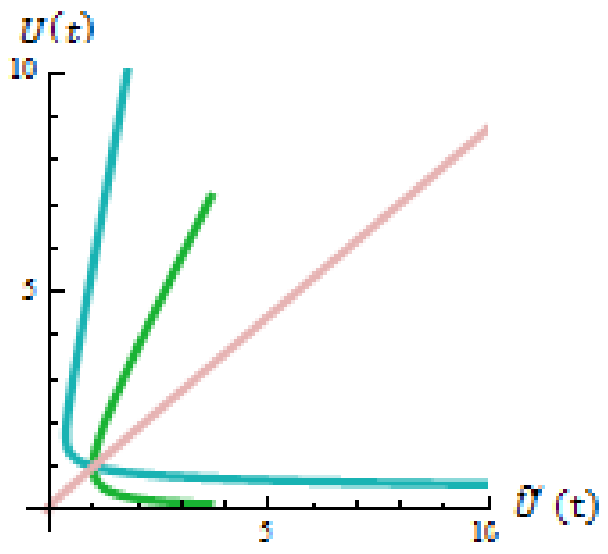

Figure 17: Utility of cycle of money with and without the enforcement savings

According to figure 17, it is concluded that the utility is higher for the public and the private sector in the normal case (green line) than in the case that there don't exist enforcement savings (pink line). The higher level of utility is in the case that there are no escaped savings (blue line). Thence, the utility of the economy and the economic dynamic has its best level in the combination that there exist the enforcement savings and not escaped savings. The enforcement savings it is obvious that they have a positive impact on the economy, and simultaneously the 
escaped savings harm the economy. The relation between these terms, escaped and enforcement savings, is connected through the cycle of money. The increase in the cycle of money stands on some key economic characteristics which showed in the next scheme:

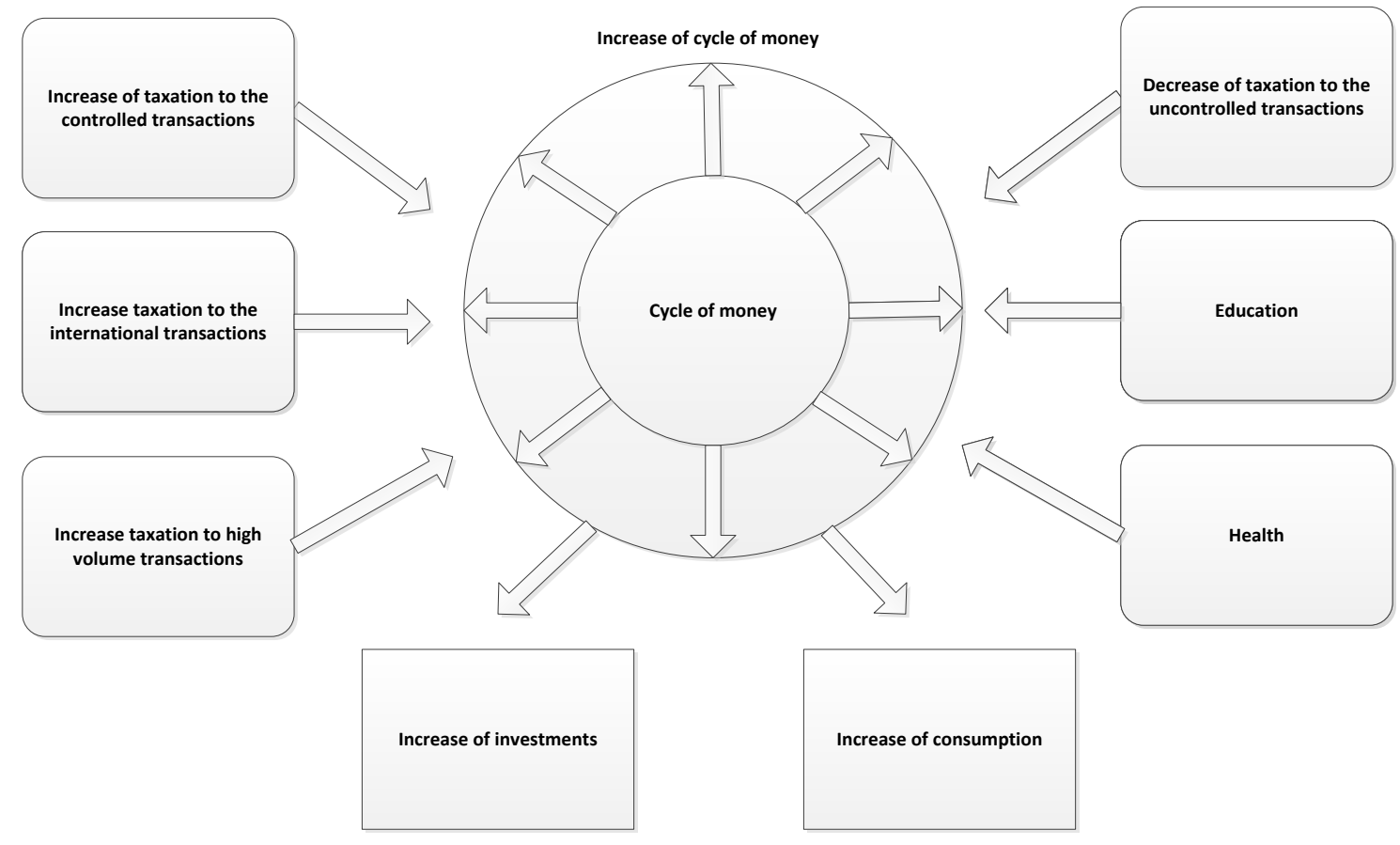

Figure 18: Increase of the cycle of money

All the economic key points and conditions, of the prior scheme of figure 18, indicate cases that there is no enforcement of the cycle of money. Thus, health, education, low taxation to uncontrolled transactions, high taxation to the controlled transactions, high taxation to the international transactions, and increased taxation to the high volume transactions, are factors that support the growth of the cycle of money. Therefore, the consumption and the investments in this economy are increased. The concept is that health and education are quality factors that increase the cycle of money, because of their significant role in the quality characteristics of an economy. The education secures that an economy will have for instance educated employees and employers, high technological knowledge, etc. The health care system secures that to an economy the citizens will be able to produce. The increased taxation in controlled transactions will lead to more uncontrolled transactions, increasing that way the tax revenue. In addition, in that case, the increase of taxation to controlled transactions will drive the economy into an increase of the cycle of money, by a boost in consumption and investments.

The decrease in the cycle of money is formed on some key elements which showed in the next scheme: 


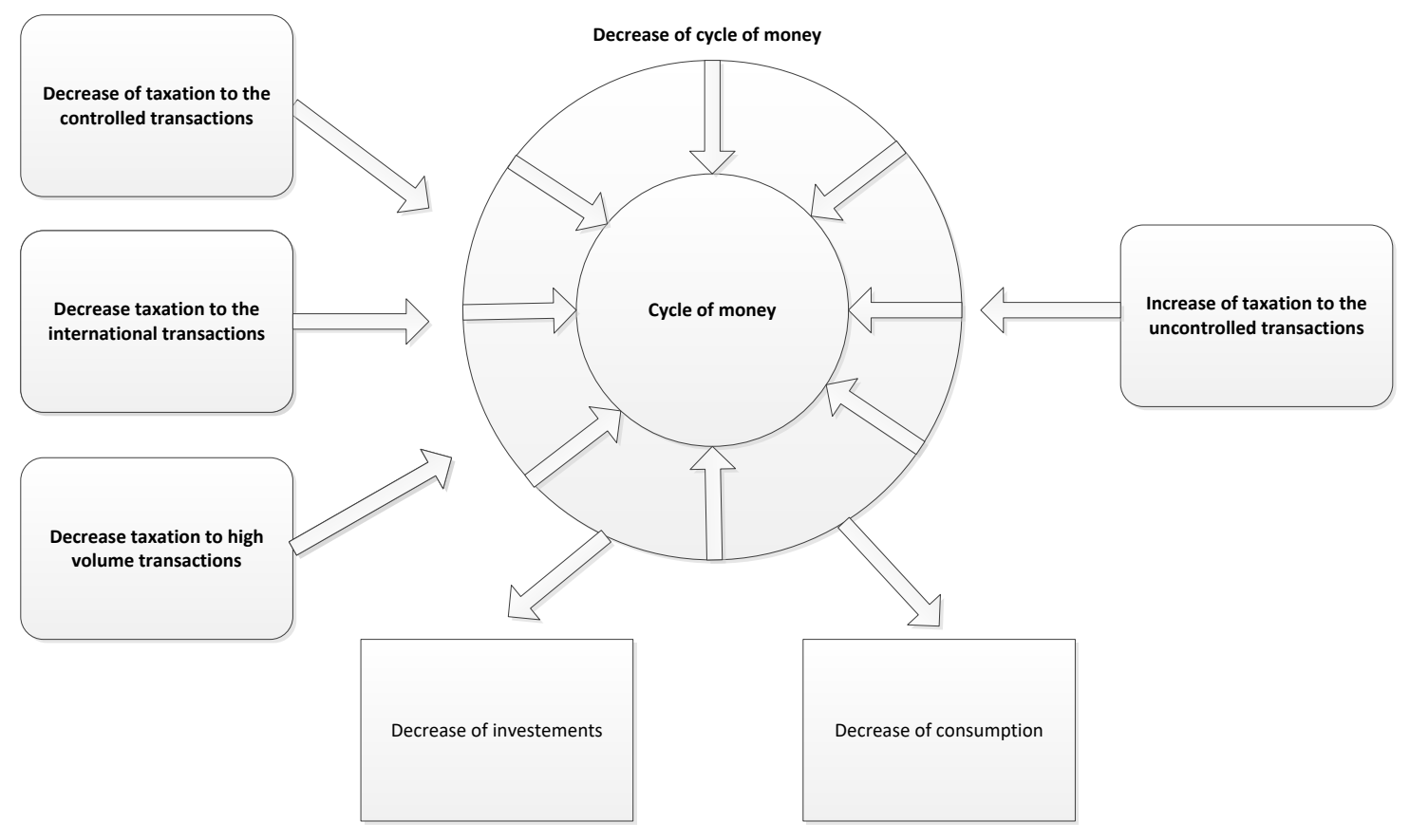

Figure 19 Decrease in the cycle of money

All the economic elements and the conditions, of figure 19, present the cases that there is a decline in the cycle of money. Thence, the absence of health, the omit of education, the high taxation to the uncontrolled transactions, the low taxation to the controlled transactions, the low taxation to the international transactions, and the low taxation to the high volume transactions, are factors that support the growth of the cycle of money. Thus, the consumption and the investments in this economy are decreased. An increase of taxation to the uncontrolled transactions will be a catastrophe for the cycle of money. Simultaneously, a decrease of taxation to the controlled transactions and international transactions could decrease the dynamic of the economy, as the escaped savings would be increased and enforcement savings would be increased. Therefore, an economic system in this condition couldn't react to an economic crisis, and contemporaneously would not be able to develop adequately.

\section{Discussion}

Applications of this theory could be found in the papers about Latvia, Serbia, Greece, Thailand, Bulgaria, etc where is found the robustness of these economies, and the ability to counteract an economic depression (Constantinos Challoumis, 2021, 2021b, 2021a). Therefore, according to the work "Index of the cycle of money - the case of Latvia", to the work "Index of the cycle of money - the case of Serbia", "Index of the cycle of money - the case of Greece", etc, all the economies have rated over the number of 0.2 which means that they are above the minimum rate of the index of cycle of money, meaning that they can face an economic crisis. For instance, Latvia is close to 0.5 meaning that can face an economic crisis. Then, more research could be made and for other countries. Moreover, from all the empirical cases it is obvious that when an economy increases the cycle of money, achieves better GDP. The escaped savings from an economy causes a decrease in the dynamic of the economy, as become weaker.

On the contrary, the reuse of money, as many times is plausible permits an amelioration of the economy. The reuse of money with high frequency allows the economy to boost, as every economic unit of the economy is used better. The context of the theory of the cycle of money is to use a certain amount of money as many times as plausible in the economy and this could 
happen by the high distribution of money in the economy. The distribution of money reflects the structure of the economy. The reason for this condition is that an economy with a certain structure is plausible to distribute the money appropriately. The best scenario is to have the big capital investments in factories and know-how technological units. Then, in that way, the smaller companies will be able to develop and to have activities without facing substitution of their commercial activities by larger enterprises.

\section{Conclusions}

In this paper, it is concluded from comparisons that the utility of the public and private sector is very high when there are enforcement savings and not escaped savings, as is expected. When there is low taxation to uncontrolled transactions and high taxation on controlled transactions the cycle of money is high (Carattini, Carvalho, \& Fankhauser, 2018; Dancygier \& Laitin, 2014; De Araujo et al., 2020; Omrani et al., 2021; Reeves, Edmunds, Searles, \& Wiggers, 2019). Therefore, the consumption and the inventions in this economy would be at their maximum level. On the other hand, when taxes are high on uncontrolled transactions and low taxes on controlled transactions, the money cycle is weak (C. Challoumis, 2020), the money cycle is weak. Then consumption and invention in this economy will be minimal. An economy with a high frequency of money cycles has better sustainability, due to a better allocation of money. The G7 decision on an overall minimum tax rate of $15 \%$ corresponds to the fixed-length principle of money cycle theory (Constantinos Challoumis, 2019a, 2019b). The structure of the economy, which is directly related to the distribution and reuse of money, is linked; demonstrates the strength of an economy in a potential crisis state.

In addition, the application of money cycle theory consists of two stages. The first stage comes from the authorities, which must introduce low tax rates for small and medium-sized businesses, and high tax rates for large companies to replace the activities of smaller companies. In this way, large companies should invest in factories and units with technological know-how. If this happens, the authorities should levy a low tax on large companies for these activities. The second stage is to create conditions for the economy to act for more appropriate perfect competition, after the fiscal policy diversified in the first step, thus facing monopolies and oligarchs. As a result, the currency turnover will be increased, improving the structural features of the economy, as better reuse and distribution of money will increase the prosperity of the country.

\section{Appendix I}

The Mathematica code (a simple system of first-order derivatives under conditions, logic of the Q.E. methodology and the Karush-Kuhn-Tucker method):

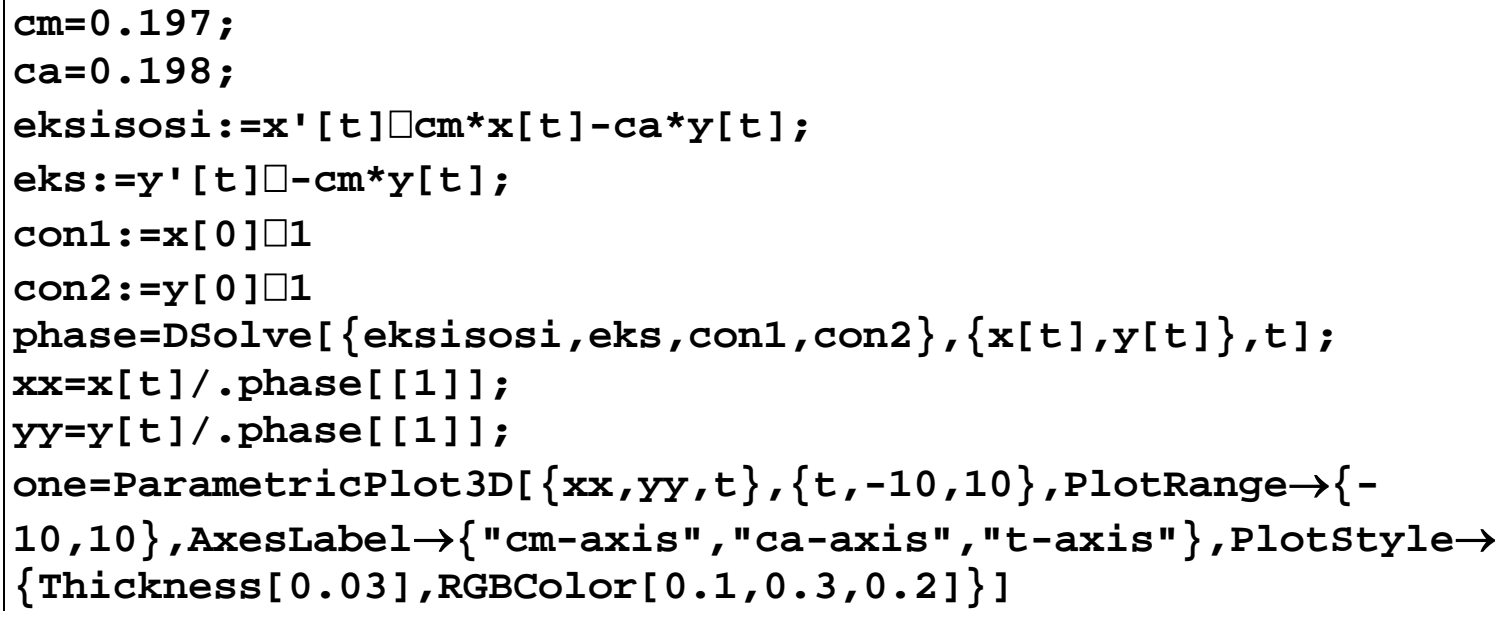


two=ParametricPlot $[\{x x, y y\},\{t,-10,10\}, P$ lotRange $\rightarrow\{-$

$10,10\}$, AxesLabel $\rightarrow\{$ "cm-axis", "ca-axis", "t-axis" $\}, P l o t s t y l e \rightarrow$ $\{$ Thickness $[0.01], \operatorname{RGBColor}[0.1,0.7,0.2]\}]$

$\mathbf{x x}$

yy

$\mathrm{cmA}=1.5$;

caA=0.32;

eksisosiA: =xA' $[t] \square \mathrm{cmA}^{*} x A[t]-\mathrm{caA}^{*} \mathrm{yA}[\mathrm{t}]$;

eksA: =yA' [t] $\square-c a A^{*} y A[t]$;

con $1 A:=x A[0] \square 1$

con2A: =yA $[0] \square 1$

phase $A=D S o l v e[$ eksisosiA, eksA, con $1 A, \operatorname{con} 2 A\},\{x A[t], y A[t]\}, t]$; $\operatorname{xxA}=x A[t] /$. phase $[[1]]$;

yyA=yA $[t] /$.phaseA $[[1]]$;

three $=$ ParametricPlot3D $[\{x x A, y y A, t\},\{t,-10,10\}, P$ lotRange $\rightarrow\{-$ $10,10\}$, AxesLabel $\rightarrow\{$ "cm-axis", "ca-axis", "t-axis" $\}, P l o t s t y l e \rightarrow$ $\{$ Thickness [0.03], RGBColor $[0.1,0.7,0.7]\}]$

four=ParametricPlot $[\{x x A, y y A\},\{t,-10,10\}, P l o t R a n g e \rightarrow\{-$

$10,10\}$, AxesLabe $\rightarrow\{$ "cm-axis", "ca-axis", "t-axis" $\}, P l o t s t y l e \rightarrow$ $\{$ Thickness [0.01], RGBColor $[0.1,0.7,0.7]\}]$

$x \times A$

YyA

Show [one, three]

Show [two, four ]

$\mathrm{cmB}=0.125$;

$\mathrm{CaB}=-0.86$;

eksisosiB: $=x B^{\prime}[t] \square \mathrm{cmB}^{*} \times B^{2}[t]-\mathrm{caB}^{*} \mathrm{yB}[\mathrm{t}]$;

eksB : =yB ' $[\mathrm{t}] \square-\mathrm{caB}^{*} \mathrm{yB}[\mathrm{t}]$;

con1B : $=x B[0] \square 1$

con2B : =yB $[0] \square 1$

phase $B=D S o l v e[$ eksisosi $B, e k s B, \operatorname{con} 1 B, \operatorname{con} 2 B\},\{x B[t], y B[t]\}, t]$; $\mathrm{xxB}=\mathrm{xB}[\mathrm{t}] /$. phaseB $[[1]]$;

yyB=yB $[t] /$. phaseB $[[1]]$;

five $=P$ arametricPlot $3 D[\{x x B, y y B, t\},\{t,-10,10\}, P$ lotRange $\rightarrow\{-$

$10,10\}$, AxesLabel $\rightarrow\{$ "cm-axis", "ca-axis", "t-axis" $\}, P l o t S t y l e \rightarrow$ $\{$ Thickness [0.03], RGBColor $[0.9,0.7,0.7]\}]$

six=ParametricPlot $[\{x x B$, yyB $\},\{t,-10,10\}, P l o t R a n g e \rightarrow\{-$

$10,10\}$, AxesLabe $1 \rightarrow\{$ "cm-axis", "ca-axis", "t-axis" $\}, P l o t S t y l e \rightarrow$ $\{$ Thickness $[0.01], \operatorname{RGBColor}[0.9,0.7,0.7]\}]$

Show [one, five]

Show [two, six]

Show [one, three, five]

Show [two, four, six] 
ParametricPlot3D $[\{x x, x x A\},\{t,-10,10\}, P l o t R a n g e \rightarrow\{-$ $100,100\}$, AxesLabel $\rightarrow\{$ "xx-axis", "xxA-axis", "z-axis" $\}$, Plotstyle $\rightarrow$ \{Thickness [0.03], RGBColor $[0.1,0.4,0.7]\}]$ ParametricPlot $[\{x x, x x A,\{t,-10,10\}, P l o t R a n g e \rightarrow\{-$ $100,100\}$, AxesLabe $\rightarrow\{$ "xx-axis", "xxA-axis", "z-axis" $\}$, Plotstyle $\rightarrow$ \{Thickness [0.01], RGBColor $[0.1,0.4,0.7]\}]$ ParametricPlot3D $[\{y y, y y A\},\{t,-100,100\}, P l o t R a n g e \rightarrow\{-$ $100,100\}$, AxesLabel $\rightarrow\{$ "y-axis", "yyA-axis", "z-axis" $\}$, Plotstyle $\rightarrow$ \{Thickness [0.03], RGBColor $[0.7,0.7,0.7]\}]$ ParametricPlot $[\{\mathrm{yy}, \mathrm{yyA}\},\{\mathrm{t},-10,10\}, \mathrm{PlotRange} \rightarrow\{-$ $100,100\}$, AxesLabel $\rightarrow\{$ "y-axis", "yyA-axis", "z-axis" $\}, P l o t S t y l e \rightarrow$ $\{$ Thickness $[0.01], \operatorname{RGBColor}[0.7,0.7,0.7]\}]$

\section{Appendix II}

To this appendix is presented the mathematical background of the theory of the cycle of money. The calculations of the cycle of money are clarified by the following mathematical types, by the work "Mathematical background of the theory of cycle of money", therefore :

$c_{y}=c_{m}-c_{\alpha}$

$c_{y}=\frac{d x_{m}}{d m}-\frac{d x_{m}}{d a}$

$i_{c y}=Y * b_{d}$

$g_{c y \text { Country }}=\frac{c_{y \text { coyntry's }}}{c_{y} \text { Average }+c_{y \text { coyntry's }}}$ or $\frac{i_{c y \text { coyntry's }}}{i_{c y \text { Average }}+i_{\text {cy coyntry's }}}$

$g_{c y \text { Average }}=\frac{c_{y \text { Average }}}{c_{y \text { Average }}+c_{y \text { Average }}}$ or $\frac{i_{c y \text { Average }}}{i_{c y \text { Average }}+i_{c y \text { Average }}}=0.5$

" The $c_{m}$ is the velocity of financial liquidity, $c_{\alpha}$ is the velocity of escaped savings and $c_{y}$ is the cycle of money. The $i_{c y}$ is the index of the cycle of money, $Y$ is the national income or GDP, and $b_{d}$ is the bank deposits of the country. In addition, $g_{c y \text { country }}$ symbolizes the general index of $c_{y}$ of the country, $i_{c y \text { coyntry's }}$ or $c_{y \text { coyntry's }}$ is the index of $c_{y}$ of the country, and $i_{c y \text { Average }}$ or $c_{y}$ Average is the global index of $i_{c y}$. Concluding, $g_{c y \text { Average }}$ is the general global index of $c_{y}$, and is obtained as a global constant (Constantinos Challoumis, 2019a, 2021, 2021b, 2021a). The proper hypothesis is to establish the connection between the index of global average $c_{y}$, the bank deposits and the GDP per capita, with an econometric approach. The eq. (25) and (26) mean that an economy close to the value of 0.5 can face immediately an economic crisis. Results close to this value represent an appropriate index of the cycle of money, revealing an adequate economic structure of the society $a n+d++$ then the fine distribution of money between the citizens - consumers. Equation (22) is the term of the cycle of money which used to define the $c_{y \text { coyntry's }}$ and $c_{y \text { Average }}$ of eq. (23). 
The cycle of money to a quantity value is expressed by GDP, basically is an expression of $\frac{\partial(\mathrm{GDP})}{\partial(\mathrm{S}+\mathrm{I}+\mathrm{X})}$, according to $\frac{d x_{m}}{d m}$ and $-\frac{\partial(\mathrm{GDP})}{\partial(\mathrm{S} /+\mathrm{I}+\mathrm{M})}$ based on $\frac{d x_{m}}{d a}$. Then, $c_{y}=d(G D P)=\frac{\partial(\mathrm{GDP})}{\partial(\mathrm{S}+\mathrm{I}+\mathrm{X})} d(\mathrm{~S}+$ $\mathrm{I}+\mathrm{X})-\frac{\partial(\mathrm{GDP})}{\partial(\mathrm{S}+\mathrm{I}+\mathrm{M})} d\left(\mathrm{~S}^{\prime}+\mathrm{I}^{\prime}+\mathrm{M}\right)$, formed on $c_{y}=\frac{d x_{m}}{d m}-\frac{d x_{m}}{d a}$, of eq, (23). Then, $\mathrm{S}$ is the savings, $\mathrm{I}$ is the investments and $\mathrm{X}$ is the exports. Then, S', is about the savings which are oriented to banks out of the country's economy, I', is about the investments which oriented to banks out of the country's economy, and $\mathrm{M}$ are the imports. Therefore, the cycle of money expresses the GDP as the following one: $Y=S_{T}+I_{T}+(X-M)$, or $Y=\left(S-S^{\prime}\right)+$ $\left(I-I^{\prime}\right)+(X-M)$ or $Y=\Delta S+\Delta I+(X-M)$. According to the theoretical background, for the lost money from the economies, the problem of controlled transactions could be administrated, if an organization could identify the money transitions between the economies, by a comparison of the global economies, by $\Delta \mathrm{S}, \Delta \mathrm{I}$, and $(\mathrm{X}-\mathrm{M})$. Thus, $c_{y \text { total }}=$ $\sum_{i=1}^{n} \sum_{t=1}^{m} c_{y i, t}=\sum_{i=1}^{n} \sum_{t=1}^{m}\left[\frac{\partial(\mathrm{GDP})}{\partial(\mathrm{S}+\mathrm{I}+\mathrm{X})} d(\mathrm{~S}+\mathrm{I}+\mathrm{X})-\frac{\partial(\mathrm{GDP})}{\partial\left(\mathrm{S}^{\prime}+\mathrm{I}^{\prime}+\mathrm{M}\right)} d\left(\mathrm{~S}^{\prime}+\mathrm{I}^{\prime}+\mathrm{M}\right)\right]_{i, t} \cdot \quad$ Because data from an organization for these activities don't exist follows the application of the index of the cycle of money. The cycle of money is an expression of the minus between the differential equations of the volume of money that is used in an economy and the volume of money that are lost from the economy. This is the reason why the theory of the cycle of money supports the higher tax of companies that make controlled transactions and in general the bigger companies for the reason that smaller companies are using an amount of money multiple times. An exemption is for the high technology companies and the factories, where their activities cannot substitute by smaller companies. Thus, if bigger companies substitute smaller companies should be taxed higher than them. Then, bigger companies should be directed by the authorities to activities that cannot be offered by smaller companies, like factories and high technological units, with beneficial, low tax rates. In that way, the money is reused multiple times in the economy" (Constantinos Challoumis, 2021c). The theory of the cycle of money is formed on GDP and could reveal from the distribution and reuse of the money, the structure of the economy.

\section{References}

Abate, M., Christidis, P., \& Purwanto, A. J. (2020). Government support to airlines in the aftermath of the COVID-19 pandemic. Journal of Air Transport Management, 89. Retrieved from https://doi.org/10.1016/j.jairtraman.2020.101931

Acs, Z., Åstebro, T., Audretsch, D., \& Robinson, D. T. (2016). Public policy to promote entrepreneurship: a call to arms. Small Business Economics, 47(1). Retrieved from https://doi.org/10.1007/s11187-016-9712-2

Aicpa. (2017). Guiding principles of good tax policy: A framework for evaluating tax proposals. American Institute of Certified Public Accountants, 2017(March 2001).

Al-Ubaydli, O., Lee, M. S., List, J. A., Mackevicius, C. L., \& Suskind, D. (2021). How can experiments play a greater role in public policy? Twelve proposals from an economic model of scaling. Behavioural Public Policy, 5(1). Retrieved from https://doi.org/10.1017/bpp.2020.17

Anguera-Torrell, O., Aznar-Alarcón, J. P., \& Vives-Perez, J. (2020). COVID-19: hotel industry response to the pandemic evolution and+ to the public sector economic measures. Tourism Recreation Research. Retrieved from https://doi.org/10.1080/02508281.2020.1826225

Bowling, S. J., Boyland, L. G., \& Kirkeby, K. M. (2019). Property Tax Cap Policy in Indiana 
and Implications for Public School Funding Equity. International Journal of Education Policy and Leadership, 15(9). Retrieved from https://doi.org/10.22230/ijepl.2019v15n9a881

Cai, Y. (2017). Nonlinear Analysis of Economic Growth, Public Debt and Policy Tools. Asian Economic and Financial Review, 7(1). Retrieved from https://doi.org/10.18488/journal.aefr/2017.7.1/102.1.99.108

Carattini, S., Carvalho, M., \& Fankhauser, S. (2018). Overcoming public resistance to carbon taxes. Wiley Interdisciplinary Reviews: Climate Change. Retrieved from https://doi.org/10.1002/wcc.531

Challoumis, C. (2020). Analysis of the Theory of Cycle of Money. Acta Universitatis Bohemiae Meridionalis, 23(2), 13-29. Retrieved from https://doi.org/https://doi.org/10.2478/acta-20200004

Challoumis, Constantinos. (2018). Methods of Controlled Transactions and the Behavior of Companies According to the Public and Tax Policy. Economics. Retrieved 21 April 2021 from https://doi.org/10.2478/eoik-2018-0003

Challoumis, Constantinos. (2019). The arm's length principle and the fixed length principle economic analysis. World Scientific News, 115(2019), 207-217. Retrieved 21 April 2021 from http:/www.worldscientificnews.com/wp-content/uploads/2018/11/WSN-115-2019-207217.pdf

Challoumis, Constantinos. (2019b). Transfer Pricing Methods for Services and the Policy of Fixed Length Principle. Economics and Business, 33(1), 222-232. Retrieved from https://doi.org/https://doi.org/10.2478/eb-2019-0016

Challoumis, Constantinos. (2021). Index of the Cycle of Money - The Case of Latvia. Economics and Culture, 17(2), 5-12. Retrieved from https://doi.org/10.2478/jec-2020-0015

Constantinos Challoumis. (2018). The Role of Risk to the International Controlled Transactions. Economics and Applied Informatics, 2018(3), 57-64. Retrieved from https://doi.org/I https://doi.org/10.26397/eai1584040917

Constantinos Challoumis. (2021). Index of the Cycle of Money - the Case of Bulgaria. Economic Alternatives, 27(2). Retrieved from https://www.unwe.bg/eajournal/en

Constantinos Challoumis. (2021). Index of the cycle of money - The case of Serbia. Open Journal for Research in Economics (OJRE), 4(1). Retrieved from https://centerprode.com/ojre.html

Constantinos Challoumis. (2021). Mathematical background of the theory of cycle of money. SSRN Electronic Journal. Retrieved from https://papers.ssrn.com/sol3/papers.cfm?abstract_id=3902181

Dancygier, R. M., \& Laitin, D. D. (2014). Immigration into Europe: Economic discrimination, violence, and public policy. Annual Review of Political Science, 17. Retrieved from https://doi.org/10.1146/annurev-polisci-082012-115925

De Araujo, V. A., Vasconcelos, J. S., Morales, E. A. M., Savi, A. F., Hindman, D. P., O’Brien, M. J., ... Garcia, J. N. (2020). Difficulties of wooden housing production sector in Brazil. Wood Material Science and Engineering, 15(2). Retrieved from https://doi.org/10.1080/17480272.2018.1484513 
Engström, G., Gars, J., Jaakkola, N., Lindahl, T., Spiro, D., \& van Benthem, A. A. (2020). What Policies Address Both the Coronavirus Crisis and the Climate Crisis? Environmental and Resource Economics, 76(4). Retrieved from https://doi.org/10.1007/s10640-020-00451-y

Feinschreiber, R. (2004). Transfer pricing Methods An Application Guide. New Jersey: John Wiley \& Sons.

Fernandez, M. A., \& Raine, K. D. (2019). Insights on the Influence of Sugar Taxes on Obesity Prevention Efforts. Current Nutrition Reports. Retrieved from https://doi.org/10.1007/s13668019-00282-4

Forson, J. A. (2020). Innovation financing and public policy dilemmas in the Economic Community of West African States (ECOWAS). African Journal of Science, Technology, Innovation and Development, 12(1). Retrieved from https://doi.org/10.1080/20421338.2019.1599575

Fronzaglia, M. L., de Moura Júnior, Á. A., Racy, J. C., \& Vartanian, P. R. (2019). Possible Effects of Economic Public Policies Implemented in Brazil after the Financial Crisis of 2008 on Foreign Direct Investment. Theoretical Economics Letters, 09(08). Retrieved from https://doi.org/10.4236/tel.2019.98176

Ginsburgh, V., \& Weber, S. (2020). The Economics of Language. Journal of Economic Literature, 58(2). Retrieved from https://doi.org/10.1257/JEL.20191316

Goldsztejn, U., Schwartzman, D., \& Nehorai, D. A. (2020). Public policy and economic dynamics of COVID-19 spread: A mathematical modeling study. MedRxiv. Retrieved from https://doi.org/10.1101/2020.04.13.20062802

Grove, A., Sanders, T., Salway, S., Goyder, E., \& Hampshaw, S. (2020). A qualitative exploration of evidence-based decision making in public health practice and policy: The perceived usefulness of a diabetes economic model for decision makers. Evidence and Policy, 15(4). Retrieved from https://doi.org/10.1332/174426418X15245020185055

Haigh, Y. (2020). Increasing complexities: Teaching public policy in the age of discontent. Teaching Public Administration, 38(1). Retrieved from https://doi.org/10.1177/0144739419879483

Jiang, X., Ding, H., Shi, H., \& Li, C. (2020). Novel QoS optimization paradigm for IoT systems with fuzzy logic and visual information mining integration. Neural Computing and Applications, 32(21). Retrieved from https://doi.org/10.1007/s00521-019-04020-3

Kamradt-Scott, A., \& McInnes, C. (2012). The securitisation of pandemic influenza: Framing, security and public policy. Global Public Health, 7(SUPPL. 2). Retrieved from https://doi.org/10.1080/17441692.2012.725752

Kananen, J. (2012). International ideas versus national traditions: Nordic economic and public policy as proposed by the OECD. Journal of Political Power, 5(3). Retrieved from https://doi.org/10.1080/2158379X.2012.735118

Loayza, N., \& Pennings, S. M. (2020). Macroeconomic Policy in the Time of COVID-19 : A Primer for Developing Countries. World Bank Research and Policy Briefs, (147291).

Lordo, R. A. (2001). Learning from Data: Concepts, Theory, and Methods. Technometrics, 43(1). Retrieved from https://doi.org/10.1198/tech.2001.s558 
Mackean, T., Fisher, M., Friel, S., \& Baum, F. (2020). A framework to assess cultural safety in Australian public policy. Health Promotion International, 35(2). Retrieved from https://doi.org/10.1093/HEAPRO/DAZ011

Maier, E. (2012). Smart Mobility - Encouraging sustainable mobility behaviour by designing and implementing policies with citizen involvement. JeDEM - EJournal of EDemocracy and Open Government, 4(1). Retrieved from https://doi.org/10.29379/jedem.v4i1.110

Michener, J., \& Brower, M. T. (2020). What's policy got to do with it? Race, gender \& economic inequality in the United States. Daedalus, 149(1). Retrieved from https://doi.org/10.1162/DAED_a_01776

Montenegro Martínez, G., Carmona Montoya, A., \& Franco Giraldo, Á. (2020). Models for public health policy analysis reported in scientific publications. Gaceta Sanitaria. Retrieved from https://doi.org/10.1016/j.gaceta.2019.11.007

OECD. (2020a). Foreign direct investment flows in the time of COVID-19. Oecd.Org, (May 2020).

OECD. (2020b). OECD Economic Surveys: Thailand 2020. OECD. Retrieved from https://doi.org/https://doi.org/10.1787/ad2e50fa-en

Omrani, H., Modroiu, M., Lenzi, J., Omrani, B., Said, Z., Suhrcke, M., \& Parmentier, B. (2021). COVID-19 in Europe: Dataset at a sub-national level. Data in Brief, 35. Retrieved from https://doi.org/10.1016/j.dib.2021.106939

Oueslati, W. (2015). Growth and welfare effects of environmental tax reform and public spending policy. Economic Modelling, 45. Retrieved from https://doi.org/10.1016/j.econmod.2014.10.040

Reeves, P., Edmunds, K., Searles, A., \& Wiggers, J. (2019). Economic evaluations of public health implementation-interventions: a systematic review and guideline for practice. Public Health. Retrieved from https://doi.org/10.1016/j.puhe.2019.01.012

Ribašauskiene, E., Šumyle, D., Volkov, A., Baležentis, T., Streimikiene, D., \& Morkunas, M. (2019). Evaluating public policy support for agricultural cooperatives. Sustainability (Switzerland), 11(14). Retrieved from https://doi.org/10.3390/su11143769

Russo Rafael, R. de M., Neto, M., de Carvalho, M. M. B., Leal David, H. M. S., Acioli, S., \& de Araujo Faria, M. G. (2020). Epidemiology, public policies and covid-19 pandemics in Brazil: What can we expect? Revista Enfermagem, 28. Retrieved from https://doi.org/10.12957/REUERJ.2020.49570

Spiel, C., Schober, B., \& Strohmeier, D. (2018). Implementing intervention research into public policy-the "I3-approach". Prevention Science, 19(3). Retrieved from https://doi.org/10.1007/s11121-016-0638-3

Tuter, C. (2020). Persepsi Masyarakat Terhadap Isu Pajak Lingkungan Di Kabupaten Kepulauan Siau Tagulandang Biaro (SITARO). Jurnal Ekonomi Dan Bisnis Airlangga, 30(1). Retrieved from https://doi.org/10.20473/jeba.v30i12020.1-13

Yen, J., \& Langari, R. (1999). Fuzzy Logic: Intelligence, Control, and Information. Prentice Hall. 